\title{
Photochromic Molecules as Building Blocks for Molecular Electronics
}

\author{
Belser Peter*
}

\begin{abstract}
Energy and electron transfer processes can be easily induced by a photonic excitation of a donor metal complex ([Ru(bpy) $\left.\left.]_{3}\right]^{2+}\right)$, which is connected via a wire-type molecular fragment to an acceptor metal complex $\left(\left[\mathrm{Os}(\mathrm{bpy})_{3}\right]^{2+}\right)$. The rate constant for the transfer process can be determined by emission measurements of the two connected metal complexes. The system can be modified by incorporation of a switching unit or an interrupter into the wire, influencing the transfer process. Such a molecular device corresponds to an interrupter, mimic the same function applied in molecular electronics. We have used organic switches, which show photochromic properties. By irradiation with light of different wavelengths, the switch changes its functionality by a photochemical reaction from an OFF- to an ON-state and vice versa. The ON- respectively OFF-state is manifested by a color change but also in different conductivity properties for energy and electron transfer processes. Therefore, the mentioned molecular device can work as a simple interrupter, controlling the rate of the transfer processes.
\end{abstract}

Keywords: Electron transfer - Energy transfer - Metal complexes · Molecular devices - Molecular electronics · Molecular switches · Molecular wires · Photochemistry · Photochromism · Photophysics ·

Polynuclear complexes

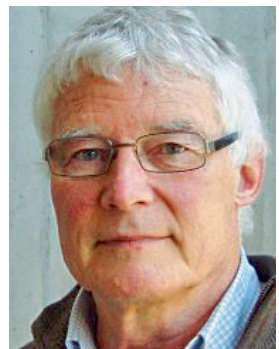

Following a laboratory technician apprenticeship at CIBA AG, Peter Belser studied chemical engineering at the engineer school in Winterthur with the final examination as dipl. chem. HTL. He got his Diploma in chemistry at the University of Fribourg and under the guidance of Professor Alex von Zelewsky he was awarded the degree of a $\mathrm{PhD}$ at the same University. Peter Belser's dissertation involved the synthesis and study of ruthenium diimine complexes. After a postdoctoral stay at the University of Fribourg he made his habilitation in inorganic chemistry at the same University. From 1992 to the present day he is associate professor at the Department of Chemistry, University of Fribourg. His main scientific topics are: Synthesis of metal complexes of ruthenium and osmium with diimine ligands and investigation of their photophysical and photochemical properties; synthesis of systems of ligands that induce an optical activity after complexation; synthesis and study of 'molecular devices' and 'molecular switches' and finally study of photochromic spin-crossover complexes.

\section{Introduction}

Molecular electronics, a fascinating topic, deals with reproducing electronic circuits and logic functions on molecular dimensions. ${ }^{[1]}$ The goal of such investigations is the miniaturization of the size of electronic chips or in other words a tremendous increase of storage density of such electronic elements. The top-down approach is limited by the wavelengths used in photolithography processes. With the best techniques applied nowadays a resolution in the range of several tens of nanometers is possible. On the other side, the bottom-up strategy to build up electronic circuits, incorporates molecular structures in sub-nanometer scale. Very simple elements like an interrupter or a diode, which work in the macro world perfectly, are not easy to realize on a molecular level. Our

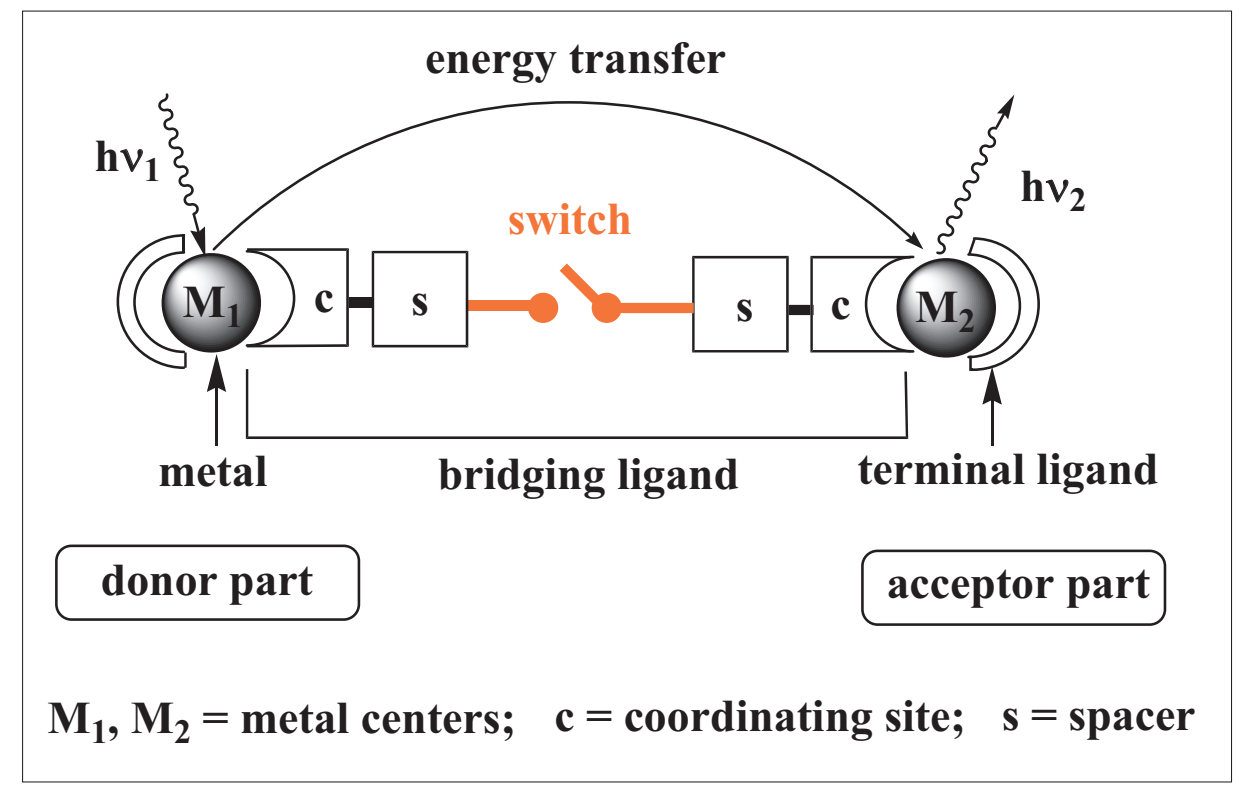


approach to building up an electronic interrupter uses the combination of photosensitive molecular units and chain-type molecules acting as wires. Fig. 1 illustrates the principle of the molecular device.

The driving force to induce an energyor electron transfer process through the wire is induced by two metal complexes, which act as a donor and acceptor unit. The metal complex ${ }^{*}\left[\mathrm{Ru}(\mathrm{bpy})_{3}\right]^{2+}$ contains enough energy in its excited state to induce the above-mentioned transfer process. As an acceptor unit the metal complex $\left[\mathrm{Os}(\mathrm{bpy})_{3}\right]^{2+}$ takes up the energy. The whole process can be observed by measuring the emission generated by the two excited metal complexes. ${ }^{[2]}$

\section{The Supramolecular System [(bpy) Ru(bpy-Anthracene-bpy) $\left.\mathrm{Os}(\mathrm{bpy})_{2}\right]\left(\mathrm{PF}_{6}\right)_{4}$}

We encountered the topic of molecular switches and molecular electronics by serendipity. During investigations on the study of energy- and electron transfer reactions in bridged, bimetallic complexes we developed a three-component system in which the two metal complex units $\left[\mathrm{Ru}(\mathrm{bpy})_{3}\right]^{2+}$ and $\left[\mathrm{Os}(\mathrm{bpy})_{3}\right]^{2+}$ are linked by an anthracene-containing bridging ligand. ${ }^{[3]}$ The goal of our investigations was the construction of a molecule in which an internal energy transfer in a predetermined direction and with a high efficiency occurs. The discussed bimetallic complex is depicted in Fig. 2 and the details of the synthesis and photophysical properties are published. ${ }^{[4]}$

The bridging ligand was prepared by a coupling reaction between 9,10-bis(chloromethyl)anthracene $\mathbf{1}$ and benzylamine under basic conditions (sodium carbonate) to yield benzyl[ $\{10-$ (benzylaminomethyl)anthracen-9-yl\} methyl]-amine 2 in good yield. The coordinating ligands 2,2'-bipyridine were introduced into the anthracene fragment by a reaction of the above-described secondary amine 2 with 2,2'-bipyridinyl-5-carbonylchloride $\mathbf{3}$ again under basic conditions (DMA/TEA) yielding the bridging ligand 4 in moderate yield. The synthesis of the bpy-anthracene-bpy bridging ligand can be seen in Scheme 1.

The corresponding monometallic complex was prepared by reaction of [Os(bpy) $\left.{ }_{2} \mathrm{Cl}_{2}\right]$ and the bpy-anthracene-bpy ligand in a 1:1 ratio, followed by an extended purification process. The second metal complex $(\mathrm{Ru})$ was then introduced by a normal procedure described in literature. ${ }^{[5]}$

Under oxygen-free conditions a very efficient energy transfer process was observed from the excited ruthenium donor moiety to the acceptor part (Os). This was indicated by an extremely short life-time of the Ru-based emission of the Ru-anthra-

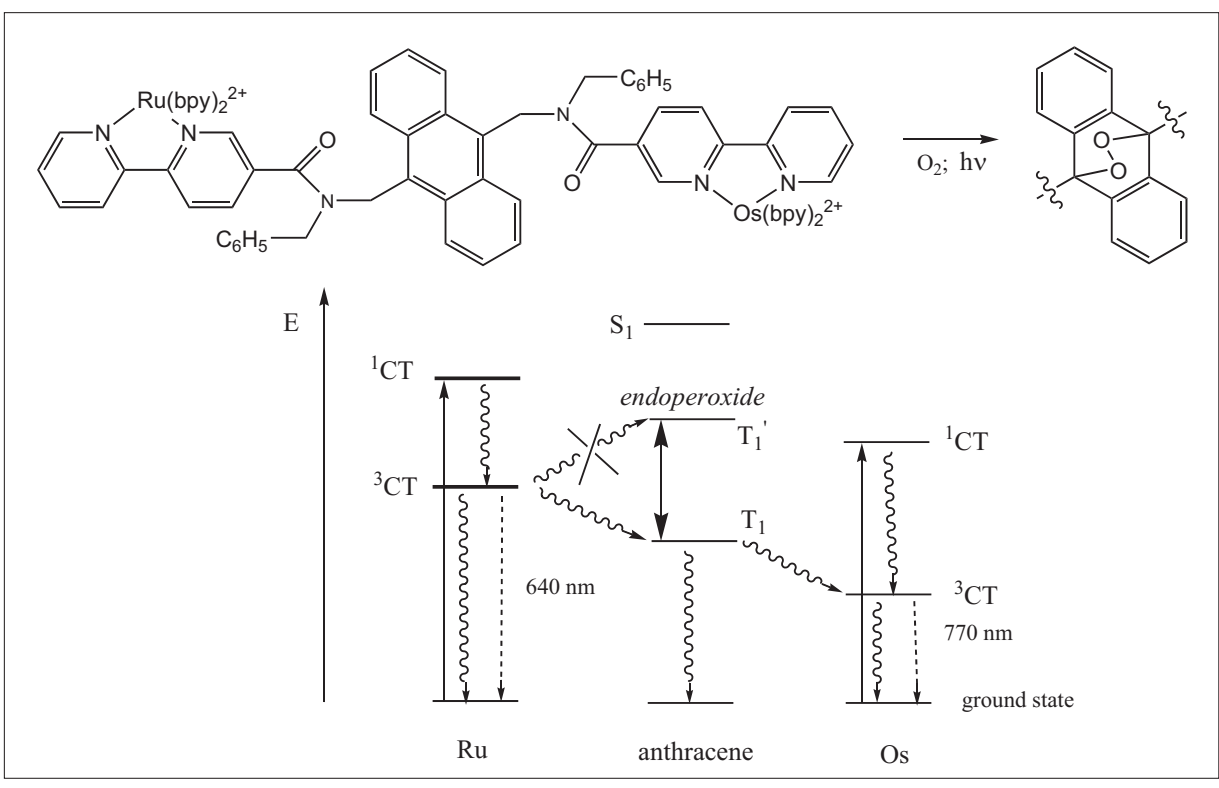

Fig. 2. The Ru-anthracene-Os system and its energy level diagram.

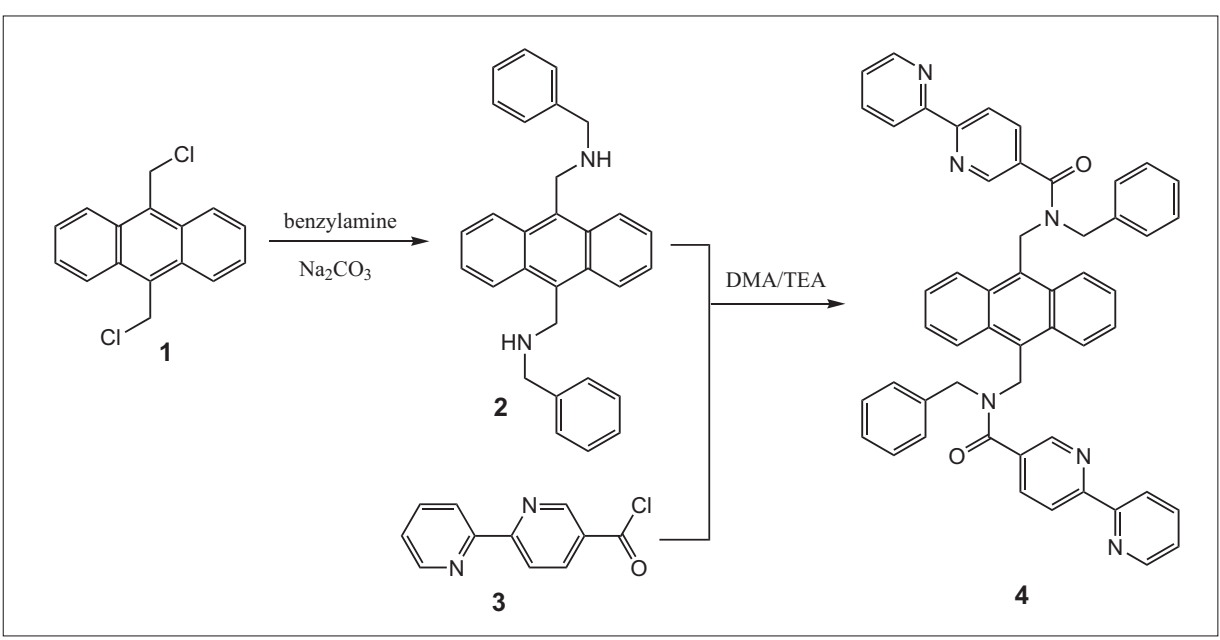

Scheme 1. The synthesis of the bpy-anthracene-bpy ligand system.

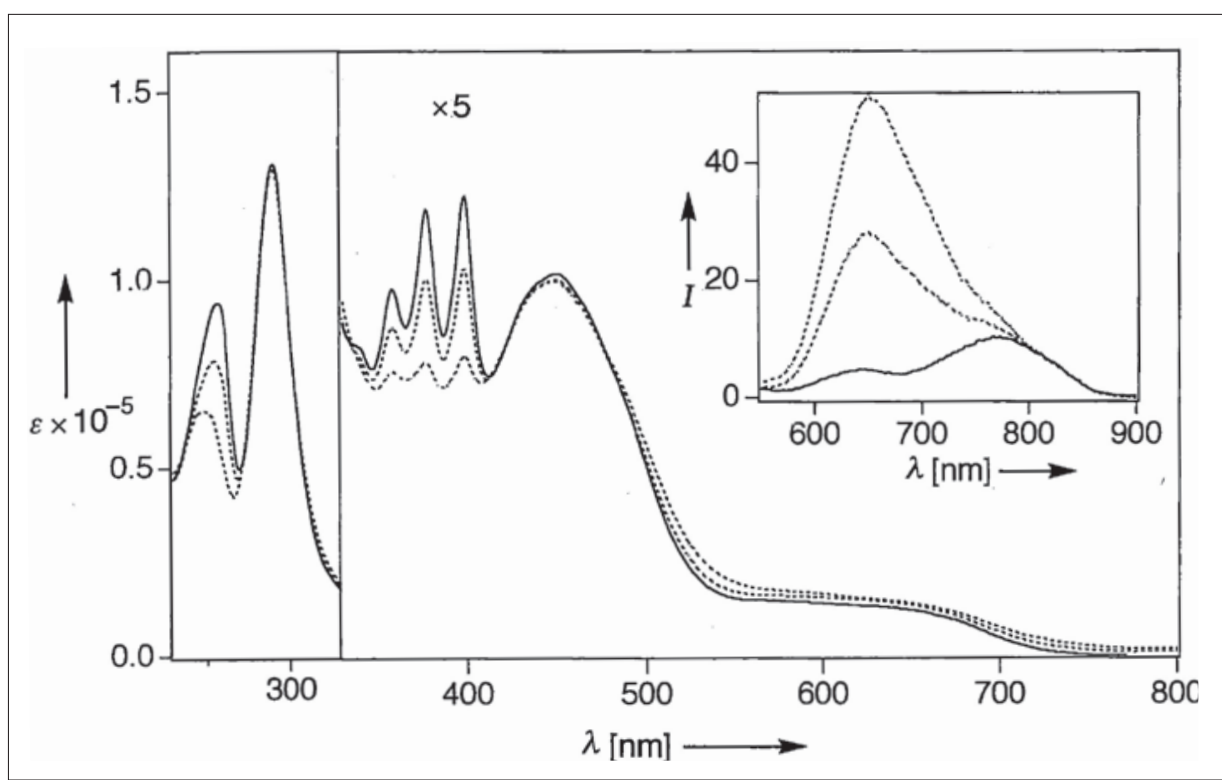

Fig. 3. Absorption and luminescence (inset) spectra of Ru-anthracene-Os (full line). Changes in spectra caused by irradiation with visible light of an aerated solution are shown (dotted lines). 


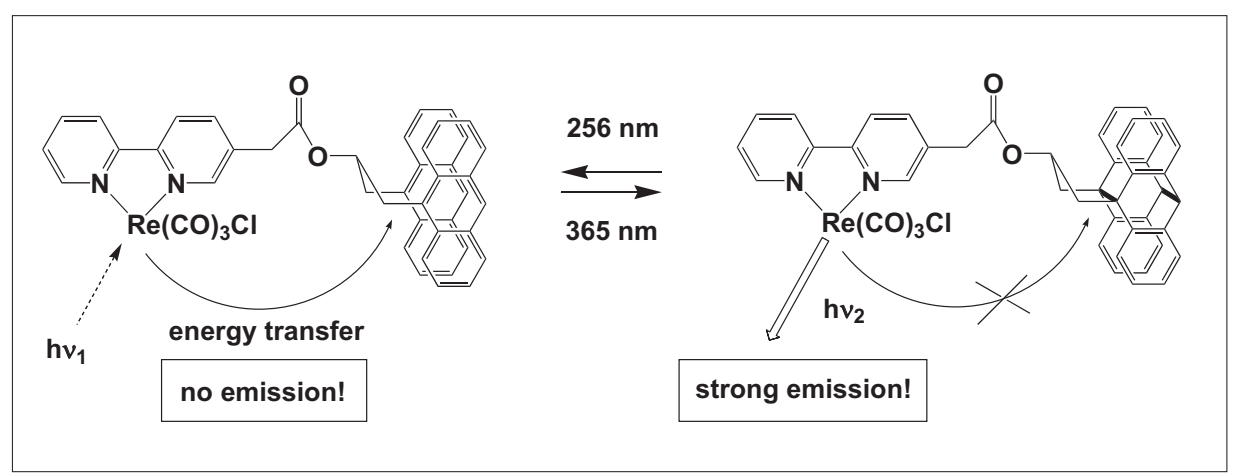

Fig. 4. A molecular switching system containing two anthracene units, which can undergo a photochemical dimerization reaction.

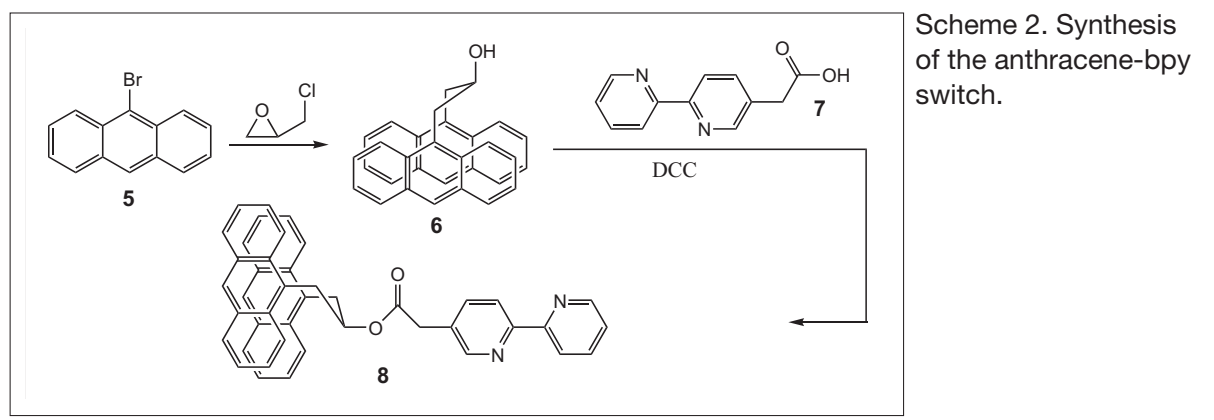

cene-Os complex (excitation at $464 \mathrm{~nm}$, corresponding to the isosbestic point of the $\left[\mathrm{Ru}(\mathrm{bpy})_{3}\right]^{2+}$ and $\left[\mathrm{Os}(\mathrm{bpy})_{3}\right]^{2+}$ subunits, see Fig. 3) compared to the corresponding model compound $\left[\mathrm{Ru}(\mathrm{bpy})_{3}\right]^{2+}$. This indicates that in Ru-anthracene-Os the ${ }^{3} \mathrm{CT}-\mathrm{Ru}$ based excited state is strongly quenched by the anthracene moiety inducing an energy transfer process to the Os-moiety. A schematic energy level diagram shown in Fig. 2 visualizes the situation.

In contrast, if the measurements were made in air-equilibrated solutions, the irradiation causes a photoreaction, indicated by the progressive disappearance of the anthracene absorption in the 350-400 nm region (Fig. 3).

In parallel, an increase in intensity of the Ru-based luminescence band at $640 \mathrm{~nm}$ is also observed (see inset Fig. 3). The photoreaction was found as a Ru-anthracene$\left({ }^{3} \mathrm{CT}\right)$-Os sensitized energy transfer to the dissolved oxygen molecules. This resulted in the formation of singlet oxygen, which was able to react with the central ring of the anthracene bridge. A careful NMR investigation has shown that the anthracene unit was oxidized to an endoperoxide species in which the anthracene aromaticity is no longer present. The energy level of the anthracene-endoperoxide moiety is significant higher than the corresponding aromatic anthracene. Therefore, the energy transfer from the $\mathrm{Ru}$ - to the Os-part is no longer possible (Fig. 2). The photochemical transformation into an anthracenen- $\mu$ peroxo unit corresponds to an OFF situation for the energy transfer process, while the bridging ligand under oxygen-free conditions acts as an ON state.

The described Ru-anthracene-Os system is one of the first described molecular switches in which an energy transfer process is interrupted by a chemical modification (endoperoxide formation). Unfortunately, the oxidation process described is not reversible and all attempts to remove the endoperoxide group failed. In conclusion, the Ru-anthracene-Os system is a molecular device for vectorial energy transfer, which undergoes 'self-poisoning' in the presence of oxygen.

\section{The Rhenium Complex $[\operatorname{Re}(\mathrm{L})$ $\left.(\mathrm{CO})_{3} \mathrm{Cl}\right] \mathrm{L}=1$,3-dianthracen-9-yl) propan-2-yl-2-([2,2'-bipyridin]-5-yl) acetate}

The above-described supramolecular system led us to a new switching system using a photochemical dimerization reaction of two anthracene units (Fig. 4). The photochromic property for that system is located in the UV region.

The system is capable of distinguishing between an ON/OFF state, a logic electronic operation on molecular dimensions. The photophysical properties are published in the literature. ${ }^{[6]} \mathrm{A}$ short overview about the preparation protocol for the synthesis of the ligand system is given in Scheme 2.

Two molecules of 9-bromoanthracene (5) were coupled with 2-(chloromethyl) oxirane (epichlorhydrine) yielding the switching unit 6. The metal coordinating part was introduced by an esterification reaction between 6 and 2-([2,2'-bipyridin]5 -yl)acetic acid (7) with the help of DCC to get the desired anthracene-bpy switch 8 . The synthesis of the ligand system and rhenium complex is described in literature. ${ }^{[7]}$

The anthracene moieties in the nondimerized form are able to quench the excited triplet state of the rhenium complex by an efficient energy transfer process. Therefore, no emission from the rhenium part can be observed. By irradiation of the rhenium complex with light close to the visible region $(365 \mathrm{~nm})$ an intramolecular $4 \pi$ $+4 \pi$-dimerization process between the anthracene units takes place. In the dimerized form the anthracene units have loosened the aromatic character in the central benzene ring and act no longer as an energy quencher. As a consequence, an intense emission from the metal center can be observed.

By irradiation with light of $254 \mathrm{~nm}$ wavelength, the dimerized form returns to the open form accompanied by a nonemissive behavior.

Such a chemically bounded bis-anthracene system is an ideal molecular switch, which can control or modulate energy/ electron transfer processes. In reality, the described system represents only a internal switch and allows no control of energy or electron fluxes in molecular wires.

Further investigations are underway to use the aforementioned switching part as a 'cyclophane' type bis-anthracene unit incorporated in a bridging ligand able to coordinate two metal centers. In conclusion, the supramolecular system described above is an interesting and functional assembly of two subunits, a photo-switchable bis-anthracene moiety and a detector that reveals the state of the switch by means of its emission properties.

\section{Controlling Energy Transfer Processes by Photoresponsive Dithienylethene Derivatives as Bridging Ligand}

A real development to build up an interrupter for energy- or electron transfer through wire-type molecules was achieved by incorporation of the well-described photochromic dithienylperfluorocyclopentene switch $^{[7]}$ between the donor $\left(\left[\mathrm{Ru}(\mathrm{bpy})_{3}\right]^{2+}\right)$ and the acceptor part $\left(\left[\mathrm{Os}(\mathrm{bpy})_{3}\right]^{2+}\right)$ of the molecular construction. ${ }^{[8]}$

The preparation protocol for the bridging ligand is given in Scheme 3 . 4-(4-Bromophenyl)-[2,2']-bipyridine (9) and 3-bromo-2-methyl-5-thiopheneboronic acid (10) are coupled together by a Suzuki reaction to get the precursor 11. A second coupling reaction between $\mathbf{1 1}$ and perfluorocyclopentene leads to the desired bridging ligand 12 in moderate yield. The 


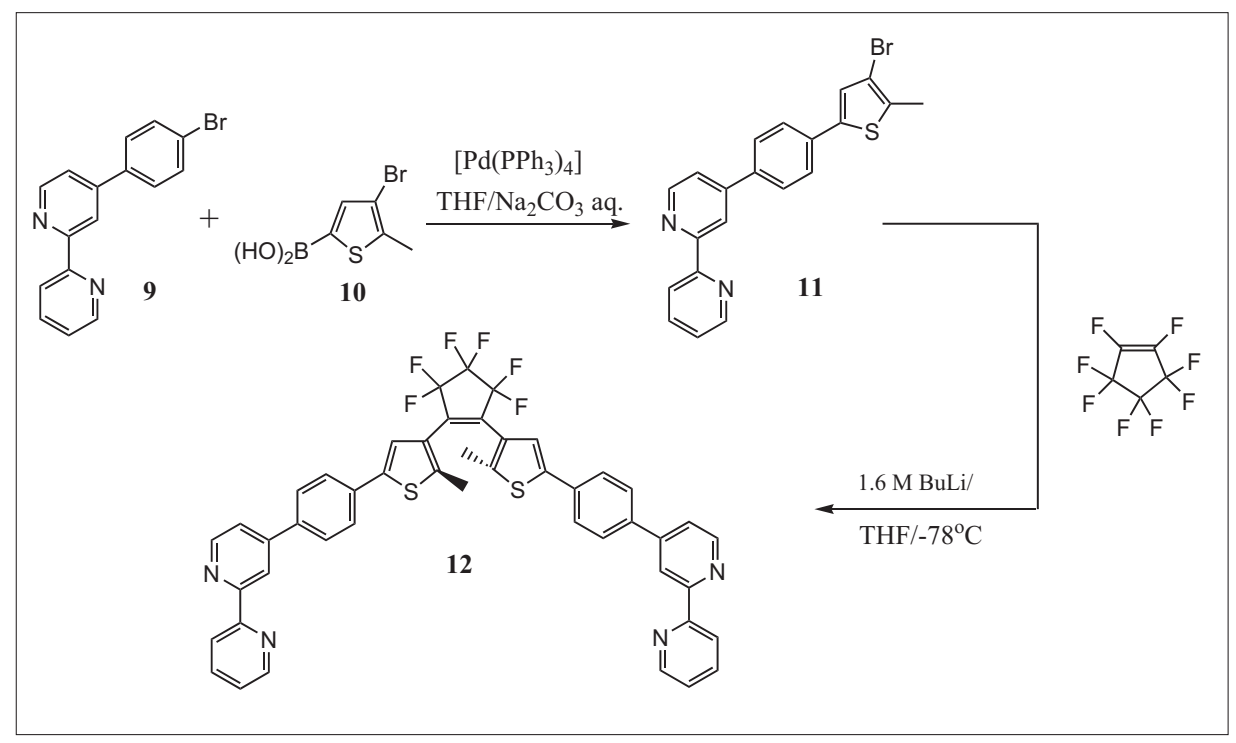

Scheme 3. Synthesis of the photochromic bridging ligand 12.

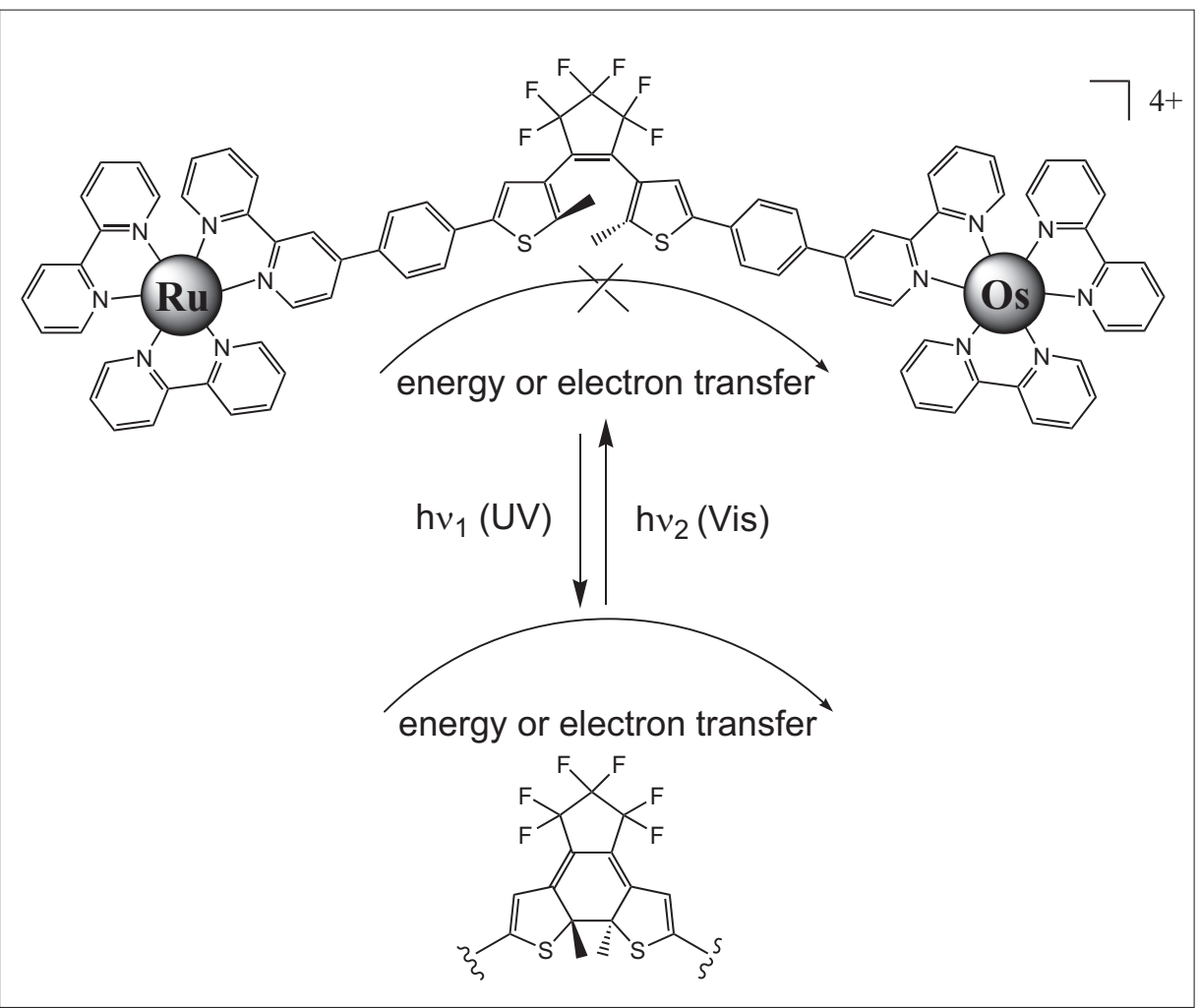

Fig. 5. The photochromic dithienylperfluorocyclopentene molecule as part of the bridging ligand.

corresponding metal complexes were synthesized according to literature methods. ${ }^{[5]}$

The switch shows a perfect bi-stable behavior and both states (open/closed respectively $\mathrm{OFF} / \mathrm{ON}$ ) can be interconverted by irradiation with light of $345 \mathrm{~nm}$ and 600 $\mathrm{nm}$ wavelengths, respectively. The properties of the complexes, Ru-switch-Ru, Osswitch-Os, and for our investigations, the most important complex Ru-switch-Os, are described in the literature. ${ }^{[5]}$ Fig. 5 shows the supramolecule in the open and closed form.

Interestingly, the switch can be photochemically closed by light of different wave- lengths. A direct irradiation with light of 345 $\mathrm{nm}$ into the ${ }^{1} \mathrm{IL}$-state, which corresponds to the closing process in the non-complexed bridging ligand, leads to the closed form. A second process, also forming the closed switch was observed. By irradiation into the ${ }^{3}$ MLCT-band of the Ru-complex, an energy transfer process to the ${ }^{3} \mathrm{IL}$-state of the switching unit occurs. The energy of the excited ${ }^{3} \mathrm{IL}$ state is high enough to induce the photochemical closing reaction of the two thienyl-fragments of the switch (Fig. 6).

If the Ru-switch-Os compound is in its open form, which corresponds to the OFF- functionality (by means of energy conductivity) of the switching system, an efficient energy transfer process via the ${ }^{3} \mathrm{IL}$ state can be observed, indicated by the strong emission from the Os-acceptor moiety and consequently very weak emission remaining from the $\mathrm{Ru}$-donor part.

In the closed system, corresponding to the ON state of the switch, an increased $\pi$-delocalization and subsequent lowering of the energy level of the switching unit is observed (Fig. 6). The consequence of such a lowering of the energy level creates a situation in which the switch acts as an energy trap. The dithienylperfluorocyclopentene switch quenches both excited states of the donor and acceptor part. For the described system with a Ru-donor and an Os-acceptor, such a behavior is unsuitable for an application as interrupter for energy or electron transfer processes. The situation changes if electrodes with an experimentally defined potential difference can be applied, replacing the donor and acceptor part in the molecule. The corresponding molecular system will be discussed in the following section of the overview. Meanwhile we have constructed a series of molecular devices with incorporated photochromic switches, showing interesting photophysical properties. ${ }^{[9]}$

\section{Molecular Electronics in Self- assembled Monolayers (SAM)}

The most fascinating approach to prove our photochromic switches is its incorporation into self-assembled monolayers (SAMs). It is well known that the preparation of SAMs is a difficult task if the molecular units, which build up the layer, contain bulky substituents. ${ }^{[10]}$ We have recently developed so-called 'tripods', able to bind via three $\mathrm{S}-\mathrm{Au}$ bonds to gold surfaces. ${ }^{[11]}$ The tripods are composed by a tetrahedral silicon core, decorated with three thiol-containing legs, and a rigid connection to the head part of the molecule. The head of the tripod can be any functionality, depending on the planned properties of the self-assembled monolayer. In our example a ruthenium complex $\left(\left[\mathrm{Ru}(\mathrm{bpy})_{2} \text { phen }\right]^{2+}\right)$ was used as the head to study photophysical properties of an immobilized metal complex on gold surface (Fig. 7). The quality of the $\mathrm{Ru}-(\mathrm{S}-\mathrm{Au})_{3}$ monolayer is depicted in Fig. 8. The AFM picture indicates islands of bounded tripods which are sufficiently large to perform local measurements and the quality and height of the layer $(3 \mathrm{~nm})$ confirm monolayer formation and its stability. Such islands are well-known for other thiolate complexes on surfaces. ${ }^{[11]}$

To study the way in which holes and electrons can flow through the molecule, tunneling junctions of SAMs of Ru-tripods 


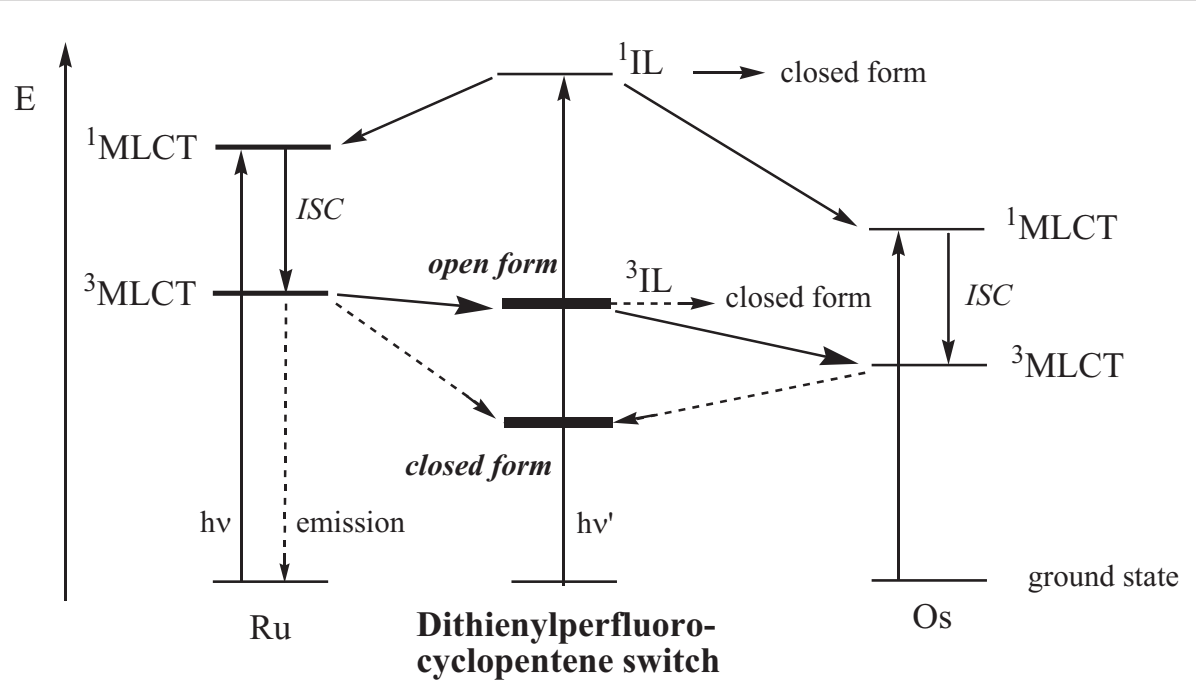

Fig. 6. Complete energy level diagram for the Ru/Os-dithienylperfluorocyclo-pentene switch.

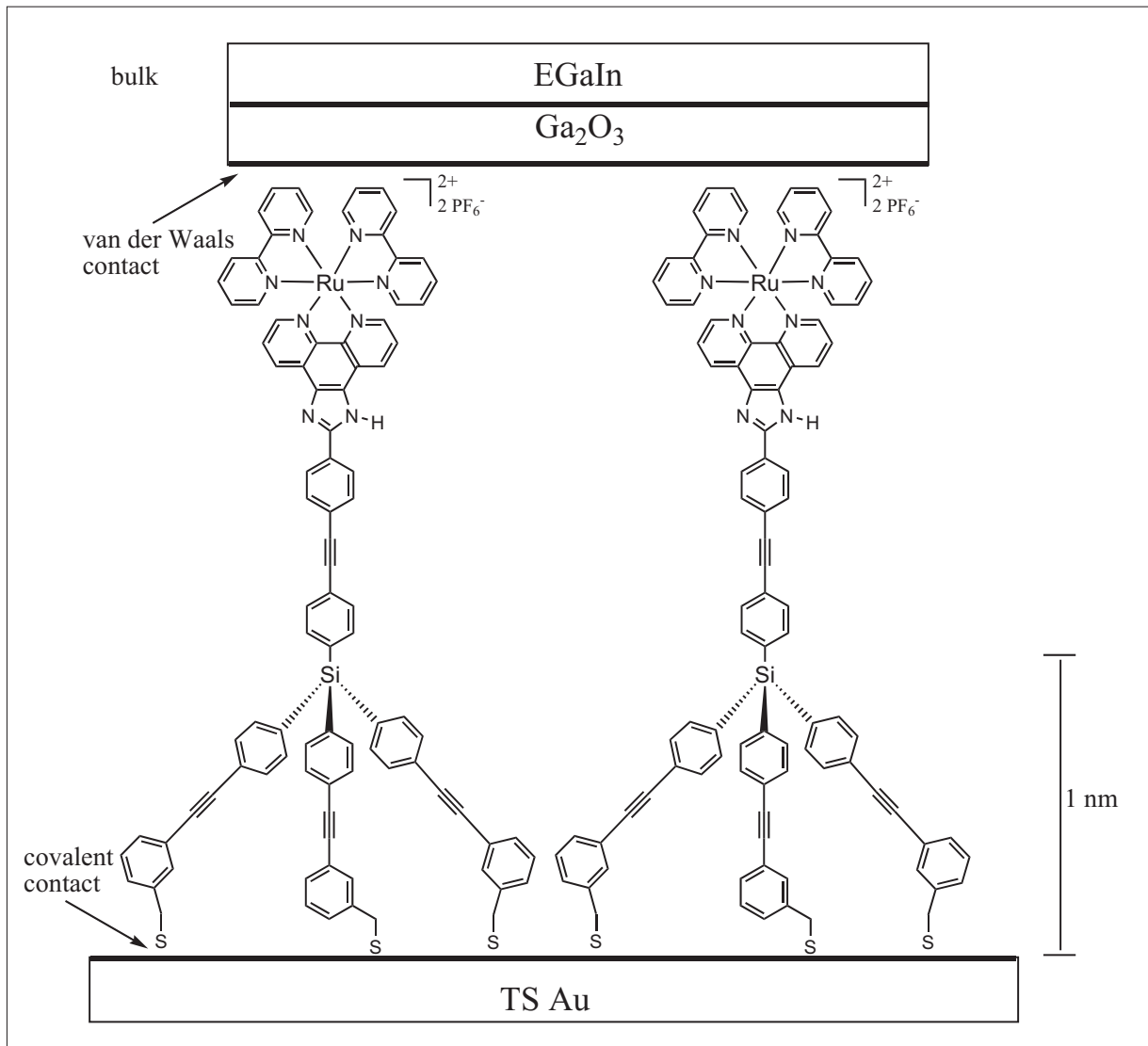

Fig. 7. Tripod molecule anchored on a gold surface and a schematic representation of the template stripped (TS) Au-Ru-tripod//EGaln tunnel junction. The EGaln top-electrode is biased while the TS Au bottom-electrode is grounded.

were formed. ${ }^{[12]}$ A conically shaped eutectic indium gallium (EGaIn) top-electrode and a template striped (TS) Au surface as bottom electrode was used to construct the tunnel junction. The EGaIn top-electrode was biased while the TS Au electrode was grounded. A typical junction size was between $500-1000 \mu \mathrm{m}^{2} .17$ junctions were assembled at three different TS Au surfaces. Of these 17 junctions, 14 were working and 3 were shorting. The junctions were then scanned between -2 and $+2 \mathrm{~V}$. The corresponding $\mathrm{J}(\mathrm{V})$ curve and the semi-log plot of a $|J|(\mathrm{V})$-curve is shown in Fig. 9. The relatively large stability and the high yield in working devices suggest that the tripod molecules are very stable and most likely constantly standing up and

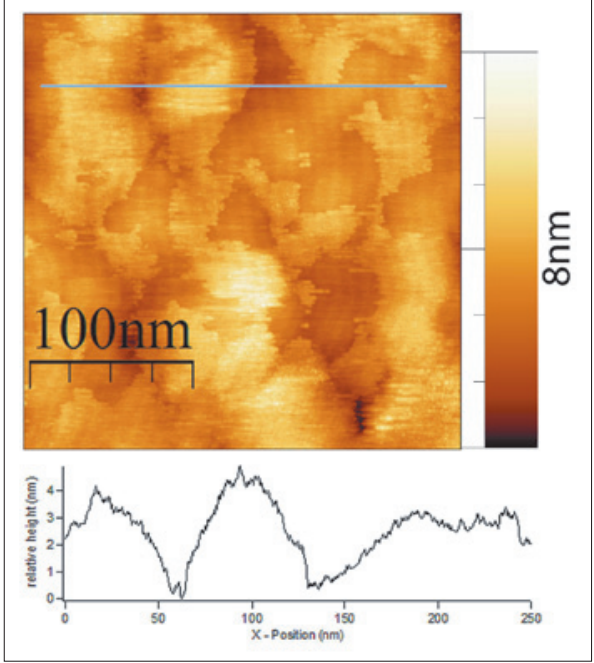

Fig. 8. AFM picture of self-assembled monolayers of Ru-tripod on a gold substrate and height profile, revealing the formation of islands whose heights correspond to the dimensions of the molecule.

the SAMs are densely packed. The TS AuRu-ripod//EGaIn junction rectify currents with a rectification ratio $\mathrm{R}=(|J|(\mathrm{V}) /|J|(-\mathrm{V}))$ $\sim 100$ at $\pm 1.5 \mathrm{~V}$. The $|J|(\mathrm{V})$-curve shows two sudden increases in current density at $-1.3 \mathrm{~V}$ and $0.9 \mathrm{~V}$. This increase in current density may reflect the on- and off-resonance tunneling of the molecular HOMO and LUMO levels of the Ru-tripod. Thus at $>0.9 \mathrm{~V}$ bias, holes are injected in the HOMO level, while $>-1.3 \mathrm{~V}$ bias electrons are injected in the LUMO. Since these processes take place at different potentials, we observed rectification with larger currents at positive bias.

A further development of such $\mathrm{Ru}$ tripod molecules is the incorporation of a photochromic switch into the rigid connecting part of molecule. Such a modification leads to a molecule whose rectification properties can be influenced. The examination of the conductivity of the SAM measured between two electrodes using a EGaIn setup demonstrated the possible application of these molecules in molecular electronics.

\section{Conclusions}

The incorporation of photochromic units into wire-type molecules opens the possibility to measure and modulate energy- and electron transfer processes. The construction of a well-working interrupter, the simplest functionality in molecular electronics, is quite difficult because each part of the whole molecule must have the right energy to fit into the molecular energy diagram. The choice to use photochromic units is given by the simple input to change the state (ON/OFF) of the switch 


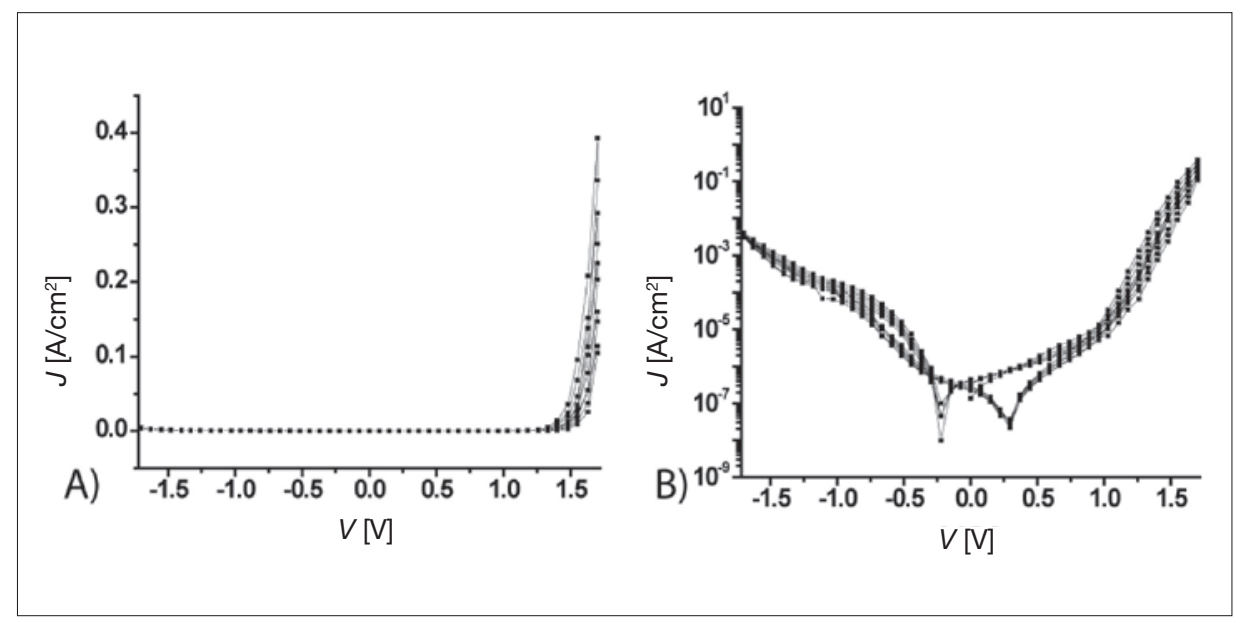

Fig. 9. A) Five $J(V)$-races of TS Au-Ru-tripod//EGaln junction and B) the corresponding $|J|(V)$ semi log-plot. One trace $=0 \mathrm{~V} \rightarrow+1.5 \mathrm{~V} \rightarrow-1.5 \mathrm{~V} \rightarrow 0 \mathrm{~V}$.

by light. If the driving force to induce the mentioned energy or electron transfer process is forced by an electrical potential difference, both actions, transfer process and change of the state of the switch, do not interfere with each other. The last example has shown that more complicated functions, for example a rectification behavior, can be combined with a molecular interrupter leading to new properties of the whole system.

Received: April 29, 2010

[1] a) W. J. Venstra, J. W. Spronck, P. M. Sarro, J. W. van Eijk, J. Micromech. Microeng. 2009, 19 , 055005; b) M. Ratner, Nature, 2005, 435, 575; c) P. Franzon, D. Nackashi, C. Amsinck, N. DiSpigna, in 'Molecular Electronics - Devices and Circuit Technology', Springer Verlag, 2007.

[2] a) L. De Cola, F. Barigelletti, V. Balzani, P. Belser, A. von Zelewsky, C. Seel, M. Frank, F. Vögtle, Coord. Chem. Rev. 1991, 111, 255; b) B. Schlicke, L. De Cola, P. Belser, V. Balzani, Coord. Chem. Rev. 2000, 208, 267; c) S. Welter, N. Salluce, A. Benetti, N. Rot, P. Belser, P. Sonar, A. C. Grimsdale, K. Müllen, M. Lutz, A. Spek, L. De Cola, Inorg. Chem. 2005, 44, 4706.

[3] L. De Cola, V. Balzani, P. Belser, R. Dux, M. Baak, Supramolec. Chem. 1995, 5, 297.

[4] P. Belser, R. Dux, M. Baak, L. De Cola, V. Balzani, Angew. Chem. Int. Ed. 1995, 34, 595.

[5] R. Jukes, V. Adamo, F. Hartl, P. Belser, L. De Cola, Inorg. Chem. 2004, 43, 2779.
[6] a) A. Beyeler, P. Belser, Coord. Chem. Rev. 2002, 230, 29; b) D. S. Tyson, D. A. Bignozzi, F. N. Castellano, J. Am. Chem. Soc. 2002, 124, 4562 .

[7] a) A. Beyeler, P. Belser, L. De Cola, Angew. Chem. Int. Ed. 1998, 36, 2779; b) P. Belser, S. Bernhard, C. Blum, A. Beyeler, L. De Cola, V. Balzani, Coord. Chem. Rev. 1999, 190-192, 155.

[8] a) V. Adamo, P. Belser, Chimia 2003, 57, 169; b) R. Jukes, V. Adamo, F. Hartl, P. Belser, L. De Cola, Coord. Chem. Rev. 2005, 249, 1327; c) P. Belser, L. De Cola, F. Hartl, V. Adamo, B. Bozic, Y. Chriqui, V, Iyer, R. Jukes, J. Kühni, M. Querol, S. Roma, N. Salluce, Adv. Funct. Mater 2006, 16, 195.

[9] a) R. T. F. Jukes, B. Bozic, F. Hartl, P. Belser, L. De Cola, Inorg. Chem. 2006, 45, 8326; b) R. T. F. Jukes, B. Bozic, P. Belser, L. De Cola, F. Hartl, Inorg. Chem. 2009, 48, 1711; c) R. Q. Albuquerque, J. Kühni, P. Belser, L. De Cola, ChemPhysChem 2010, 11, 575.

[10] A. D'Aleo, R. Williams, Y. Chriqui, V. Iyer, P. Belser, F. Vergeer, V. Ruiz, P. R. Unwin, L. De Cola, Open Inorganic Chemistry Journal 2007, $1,26$.

[11] a) T. Y. Dong, L. C. Huang, C. P. Chen, M. C. Lin, J. Organomet. Chem. 2007, 692, 5147; b) K. Terada, K. Kobayashi, Dalton Trans. 2008, 4846.

[12] S. Ramachandra, K. C. Schuermann, F. Edafe, P. Belser, C. A. Nijhuis, G. M. Whitesides, L. De Cola, Inorg. Chem. 2010, submitted for publication. 